\title{
Trazando la Nación. La cartografía como respuesta a la emergencia de identidad nacional en los Estados Unidos Mexicanos y la Nueva Granada
}

\author{
Tracing the Nation. The Cartography in Response to the Emergence of National Identity in \\ Mexico and the New Grenade
}

\author{
Carlos F. Suárez Sánchez ${ }^{a}$
}

\begin{abstract}
:
Much of the nineteenth century in Latin America, is defined as a time of uncertainty that inhabited a place between the longing for the recent colonial past and the need to find an identity based on the difference, a constant contradiction that responds with the objectives of the emancipatory disputes, the internal conflicts and the desire to consolidate the project of the young nations. Both cartographic commissions and explorers were consolidated as milestones that inaugurated a cultural tradition in an era where the realization of scientific expeditions and the representation of the own left an image in the depths of Latin American consciousness. This article compares the socio-political and economic contexts of Mexico and Colombia, in the first third of the 19th century, to reconstruct the way in which cartography became the ideal response to a state of identity emergency understood as the conglomerate of an economic disorder and territorial instability, becoming the most effective tool for the construction of the nation's imaginary, which allowed to identify a territory combined with the symbolic construction of a map, that is, to draw the nation.
\end{abstract}

Keywords:

Cartography, Nation, Latin America, Colombia, Mexico, Imaginary

\section{Resumen:}

Gran parte del siglo XIX en América Latina, se define como una época de incertidumbres que habitaba un intersticio entre el anhelo del pasado colonial reciente y la necesidad de encontrar una identidad fundamentada en la diferencia; una contradicción perenne que comulgaba con los objetivos de las luchas emancipadoras, las constantes guerras intestinas y los deseos de consolidar el proyecto de las jóvenes naciones. Tanto las comisiones cartográficas, como los exploradores, se consolidaron como hitos que inauguraron una tradición cultural en una época donde la realización de viajes investigativos y la representación de lo propio se arraigaría en lo más profundo de las raíces culturales americanas. En este artículo se parte de la comparación de los contextos sociopolíticos de dos casos particulares, los Estados Unidos Mexicanos y la Nueva Granada, procurando reconstruir el modo en que la cartografía se convirtió en la respuesta idónea ante un estado de emergencia identitaria, derivada del desconocimiento geográfico, las carencias económicas y la inestabilidad territorial, transformándose en la herramienta más eficaz para la construcción del imaginario de nación, el cual le brindó a las comunidades la capacidad de identificar un territorio aunado a la construcción simbólica de un mapa, trazando así la nación.

\section{Palabras Clave:}

Cartografía, Nación, América Latina, Colombia, México, Imaginario

\section{Naciones e imaginarios}

Es un hecho ampliamente conocido que el siglo XIX en América Latina es un periodo caracterizado fundamentalmente por el intento de conformación de los proyectos nacionales tras los sangrientos y complejos procesos de emancipación del sistema colonial europeo. Si durante los tres primeros siglos de colonia la corona fungió como principal órgano rector, enarbolando la santa voluntad de la iglesia como instancia última y método de persuasión y conquista, el siglo XIX es la transición hacia un régimen de control social de orden institucional, fincado en la figura de la nación. Junto con ello, el papel de las artes se fue desvinculando paulatinamente de la labor eclesiástica, para encontrar un nuevo mecenas con diferentes preferencias y exigencias, así pues, "[...] los artistas se adaptaron a los nuevos tiempos, en esa transformación que significó pasar de los "Santos 
Patronos" a los "Padres de la Patria" como motivo de representación." (Gutierrez Viñuales, 2003, pág. 342)

Los efectos de este fenómeno decimonónico son reafirmados constantemente por posturas que enaltecen el rol de la nación como principal fuente de definición territorial y social, pues "[...] el nacionalismo pareciera ser uno de los «ismos» con mayor capacidad de supervivencia. Esta podría derivarse de su enorme funcionalidad en estrategias de tipo político, pero no menos de su [...] relación con la «identidad» del hombre moderno." (García García, 1994, pág. 165) El concepto de nación se dibuja entonces como una piedra angular para la comprensión de la historia decimonónica de nuestros territorios, pues coincidiendo con las observaciones de Eric Hobsbawm (1991), "[...] los últimos dos siglos de la historia humana del planeta Tierra son incomprensibles si no se entiende el término nación". (pág. 9)

El continente americano parece haberse erigido como un vehículo de verificación de los modelos de nación que se habían construido en algunas latitudes europeas; los cuales podrían reducirse -no sin ser drásticos- a los dos más exitosos: 1. El de nación esencialista o modelo étnico-cultural de origen alemán, que exalta el valor de la raza y las obligaciones que derivan de pertenecer a ella, y 2. El de nación cívica o modelo voluntarista francés, que enarbolan una construcción comunitaria de nación a la cual se acogen sus integrantes por voluntad propia (Pérez Vejo, 2003). Empero este diagnóstico pueda resultar más o menos acertado como genealogía de las naciones latinoamericanas, pero en realidad, "[l]ejos de ser una pobre imitación de Europa o los Estados Unidos, o un híbrido subdesarrollado, en América Latina se ofreció un camino diferente a la construcción de la nación [...]" (Centeno y Ferraro, 2013, pág. 3) que, en consecuencia, requiere una particular atención.

Podría partirse aduciendo que "[s]in importar si sus orígenes se basan en etnicidad, cultura, historia compartida o artesanía estatal, la literatura concibe, sin embargo, a la nación como una comunidad de identidad [...]". (López Alves, 2013, pág. 284) Varías observaciones generales podrían realizarse también en torno al concepto de nación, entre ellas que es la respuesta más exitosa a los problemas identitarios post-independentistas, que la nación, como la invención que es, no es universal o sempiterna, y que "[...] la nación sería la respuesta concreta a los problemas de identidad y de legitimación del ejercicio del poder creados por el desarrollo de la modernidad." (Pérez Vejo, 2003, pág. 278)

Es evidente pues, comprendiendo la importancia del concepto nación, que el afán de su óptima constitución colmara el panorama político, económico y cultural decimonónico latinoamericano. En consecuencia, el proceso de conformación de las naciones constituye un escenario de inestabilidad en la gran mayoría de los sectores de la sociedad, incluyendo, desde luego, el de la producción de imágenes. Para Gutiérrez Viñuales (2010) en las primeras décadas del XIX "[...] los nuevos procesos de sistematización nacional se presentarán harto dificultosos y repercutirán de manera indeleble en el devenir cultural. Nos encontramos ante una América cargada de pasado y repleta de futuro, pero con un presente precario." (pág. 599) No obstante, dicha precariedad, fruto del clima de inestabilidad política, trajo consigo un periodo de fertilidad artística profundamente enraizado en la imperante necesidad de encontrar formas propias de identidad. El claro resultado de ello es que, a lo largo del siglo XIX, pero fundamentalmente en las postrimerías del mismo, surgió un espíritu plástico de confrontación frente a toda aquella reminiscencia de estéticas anteriores, el cual no se reducía a la llana imitación de las vanguardias europeas, sino que se alimentaba de una decidida intención de encontrar algo propio en las nuevas formas, aunque bien sea dicho, influida por claros modelos que derivaban de una larguísima tradición colonial. (Pini, 1997, pág. 5) Existe pues una clara tensión en los valores identitarios que oscilaba entre el reconocimiento de un pasado que había definido las prácticas artísticas durante tres siglos de dominio español y la necesidad de nuevas fórmulas estéticas que desdeñaran todo vínculo con España, sobre todo para los casos de la Nueva Granda -hoy Colombiay los Estados Unidos Mexicanos.

Este fenómeno de reapropiación de los modelos europeos y la incesante búsqueda de lo propio a través de la resignificación de las herencias coloniales, vislumbran dos procesos en una relación crítica: 1 . El de la construcción de la nación a partir de los vestigios y 2 . El de la imaginación de la misma a través de una búsqueda de lo propio. Si bien puede entenderse que ambos son las dos caras de una misma moneda, resulta arriesgado afirmar que sean proceso similar. De hecho, es preciso aclarar que "[l]a forma en que se define o concibe la nación difiere de cómo se la "imagina". La conceptualización significa un proceso mental que, aunque está conectado a la imaginación, no es lo mismo [...]" (López Alves, 2013, pág. 283), el imaginario nacional funge como derrotero para la construcción de la nación. Benedict Anderson (1993) sienta las bases para comprender el proceso de imaginación la nación, al proponer

[...] la definición siguiente de la nación: una comunidad política imaginada como inherentemente limitada y soberana. Es imaginada porque aun los miembros de la nación más pequeña no conocerán jamás a la mayoría de sus compatriotas, no los verán ni oirán siquiera hablar de ellos, pero en la mente de cada uno vive la imagen de su comunión. [...] Se 
imagina soberana porque el concepto nació en una época en que la ilustración y la Revolución estaban destruyendo la legitimidad del reino dinástico jerárquico divinamente ordenado. [...] Por último, se imagina como comunidad porque, independientemente de la desigualdad y la explotación que en efecto puedan prevalecer en cada caso, la nación se concibe siempre como un compañerismo profundo [...]. (págs. 23-25)

Pero si puede hablarse de la nación como una comunidad imaginada, no resulta descabellado pensar que pueda construirse un imaginario de nación. Lo imaginario aporta el potencial de la idealización al fenómeno de la edificación de un proyecto nacional y vincula la imagen como herramienta fundamental para su propia consecución. Para comprenderlo mejor se asumirá que

[...] un imaginario es la manera en que una sociedad ordena las representaciones que se da a sí misma. Una forma de hacer del mundo algo ordenado e inteligible, que encuentra su fundamento en una sucesión de imágenes mentales que tienen su representación, en algunos casos, en un discurso más o menos articulado. Un imaginario tiene una enorme eficacia puesto que sirve para homogeneizar mensajes y normalizar valores sociales que, a partir de ese momento, aparecen como naturales y cotidianos. La articulación del discurso de un imaginario a través de las imágenes conlleva la creación de unas pautas de narración visual y unas reglas de representación que son comprendidas y aceptadas por la sociedad a la que van dirigidas, y que siempre se refieren a valores que están más allá de la mera apariencia realista de las imágenes. (García, 2011, pág. 40)

Es fundamental notar la dimensión utilitaria del imaginario como elemento homogeneizador de mensajes y normalizador de valores que sirven a la formación de la estructura de la nación. Pero más importante aún: los imaginarios, requieren de lo que se comprende como creación de unas pautas de narración visual y unas reglas de representación, lo cual corresponde exactamente con los modelos representativos que las imágenes cartográficas decimonónicas pretendían promulgar, aglutinando los elementos esenciales para el proceso de imaginación y posterior representación de la nación.

\section{La cartografía y el arte como alternativa}

El fenómeno de la búsqueda de la identidad nacional en el contexto decimonónico de América Latina, osciló entre las expresiones artísticas amparadas bajo el yugo de una afanosa necesidad de consolidar un imaginario de nación y la re-definición del territorio. "La nación en América Latina fue concebida intrínsecamente conectada al entorno natural y la ubicación geográfica. [...] En otras palabras, se pensó que la nación representaba más las características físicas del entorno que la comunidad de hombres y mujeres que vivían con ella." (López Alves, 2013, pág. 285)

En consonancia, las artes y la cartografía se ofrecieron como las mejores herramientas para consolidar ambos objetivos. Las artes, en particular los motivos pictóricos, vieron desplazada la larga tradición iconográfica religiosa virreinal por la exaltación retratística de los próceres, las alegorías de los mitos fundacionales, la épica bélica, y desde luego la pintura de paisaje y la vasta producción de vistas y costumbres de diversos territorios. (Gutiérrez Viñuales, 2010, pág. 602) Por su parte, la cartografía ofreció una solución a los problemas de definición geográfica que el continente americano había heredado de la época colonial. Aunque es ampliamente conocido el sueño decimonónico de una gran nación Sudamericana o Centroamericana, dichos proyectos no lograron consumarse debido, no sólo al ocaso de los próceres que los sustentaban, sino también a una cuestión de ingobernabilidad en virtud de la magnitud del territorio que originó rencillas políticas surgidas durante el cruento proceso emancipatorio. Empero, una de las razones que mejor explican la tendencia a la escisión territorial es el fenómeno de la sub identidad, amparado en la tradición de lo que puede denominarse lealtades locales: un imaginario regional que sienta sus bases en las disposiciones territoriales del sistema colonial, las cuales, aunque arbitrarias en principio, terminaron por marcar pequeñas comunidades arraigadas en villas, ciudades, capitanías o cantones, que tardaron en perder hegemonía en favor de novel proyecto nacional. Una querella que, en la gran mayoría de los casos, fracturó las identidades más débiles. (Elliot, 2010, pág. 47)

La incertidumbre limítrofe se constituyó como el principal obstáculo para la ratificación del imaginario nacional. Dicha problemática no fue devenida únicamente de las postrimeras decisiones Borbónicas, sino de lo que se conoció como el principio de Uti possidetis Juris, una herramienta legal de disposición del espacio limítrofe a través de la cual las entidades nacionales buscaban reclamar la soberanía sobre territorios que históricamente les habían pertenecido. Más precisamente, el empleo del Uti possidetis pretendía respetar el pacto realizado entre España y Portugal durante el llamado Tratado de Madrid de 1750 , con el cual "[...] las naciones iberoamericanas debían conservar los dominios territoriales a su cargo al momento de la Independencia, aunque la delimitación 
definitiva no había sido aún acordada con los países vecinos." (Díaz et al., 2013, pág. 147) El Uti possidetis trastocó, en muchos casos, las lealtades locales vinculándolas a entidades administrativas más lejanas o menos afines, situación que concluyó con una disección geográfica. Dicho fenómeno se vio ejemplificado en el fallido proyecto colombiano -conocido como la Gran Colombia-, cuyo territorio total, una reminiscencia de las disposiciones coloniales del Virreinato de la Nueva Granada, fue desmembrado por lealtades locales más arraigadas. Del mismo modo, las jóvenes naciones hispanoamericanas que se vieron beneficiadas por la herencia territorial colonial, entraron en disputa con antiguas capitanías generales y entidades menos demarcadas durante los tres siglos de dominio europeo, sentando así las bases de largos -y aún existentesconflictos limítrofes en la región.

La soberanía, definida anteriormente como un eje central del proceso de imaginación de la nación, se vio gravemente comprometida al no tener claros los límites de aquello que se pretendía defender. Es insoslayable el hecho de que la soberanía está intrínsecamente ligada a la definición del territorio, pues "[l]a nación se imagina limitada porque incluso la mayor de ellas, [...] tiene fronteras finitas, aunque elásticas, más allá de las cuales se encuentras otras naciones." (Anderson, 1993, págs. 24-25) Así pues, se comprende la capital importancia que la definición del territorio tenía en el proceso de la construcción de la imagen de la nación. Antonio García Cubas refería en el primer capítulo de The Republic of México in 1876, un dato que resulta revelador: la frontera sur, colindante con la novel República de Guatemala, no estaba aún definida. Este no es un dato menor, si se considera además que la primera carta geográfica completa del estado mexicano, Carta general de la Republica Mexicana de 1858, fue elaborada por el mismo autor. En ella puede observarse, sin lugar a confusión, la falta de delimitación territorial con su vecino del sur, mientras que con los Estados Unidos se ve perfectamente marcada, ya fuese por disposición de sus vecinos, o por necesidad de defender su soberanía de una nueva invasión (Imagen 1).

Del mismo modo, para el caso Neogranadino puede citarse a uno de los padres de la geografía nacional. En 1807, Francisco José de Caldas, hijo de la Expedición Botánica y uno de los principales cultivadores de la bien ponderada ilustración santafereña, afirmaba que "[l]os conocimientos geográficos son el termómetro con que se mide la ilustración, el comercio, la agricultura y la prosperidad de un pueblo. Su estupidez y su barbarie siempre es proporcionada a su ignorancia en este punto [...]" (pág. 1163), a lo cual agregaba "[n]uestros ríos y nuestras montañas nos son desconocidos, no sabemos la extensión del país en que hemos nacido, y nuestra geografía está en la cuna." (pág. 1177)

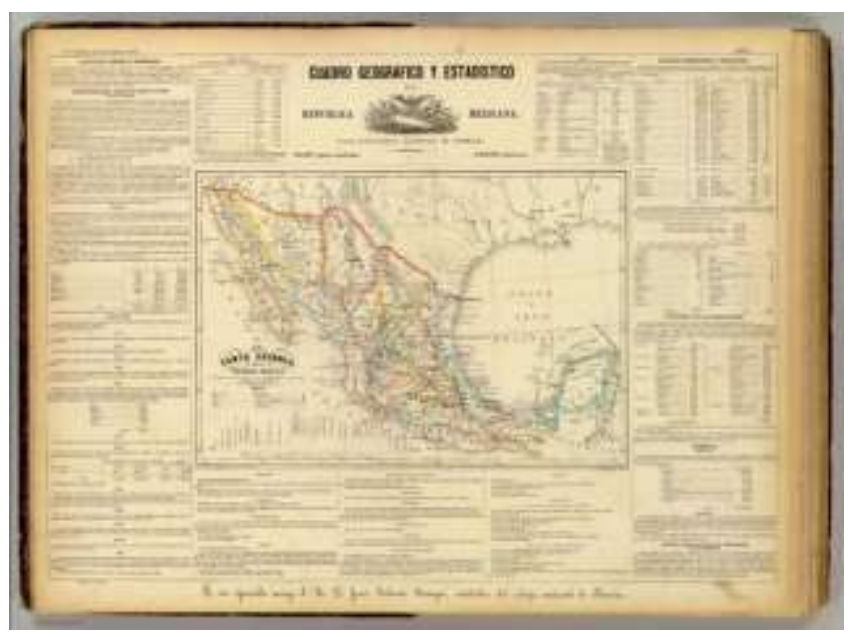

Imagen 1. Antonio García Cubas. Carta general de la Republica Mexicana, 1858. En Atlas geográfico, estadístico e histórico de la Republica Mexicana, formado por Antonio García y Cubas. México. Imprenta de José Mariano Fernández de Lara, calle de la Palma numero 4. 1858.

Ambos casos, no son más que una fehaciente muestra del desconocimiento limítrofe y territorial que embargó a las naciones latinoamericanas, casi hasta el final del siglo XIX. Pero si la penosa falta de soberanía es apenas justificable basándose en las contrariedades hasta aquí expuestas, resulta aún más difícil creer que una región explorada durante más de trescientos años por las autoridades cartográficas de los imperios europeos incluyendo la extensa tradición portuguesa y española desde el inicio mismo de la colonia- no hubiese sido delimitada y que dichos estudios no fueran consultados por los ilustrados criollos de las nóveles naciones hispanoamericanas. No obstante la gran mayoría de los mapas producidos durante la colonia jamás llegaron a manos de los cartógrafos hispanoamericanos que, empeñados en la construcción identitaria de la nación, se enlistaron en las diversas expediciones que recorrieron los territorios en busca de sus límites. La razón de este desaguisado puede ser rastreada hasta la conformación de la Casa de Contratación de Sevilla, creada en 1503. El afán de la Corona Española por mantener bajo control, tanto la producción cartográfica sobre sus posesiones en las Indias Occidentales, como las rutas de comercio marítimas que conectaban el Nuevo Mundo con Europa, la llevaron a crear la institución hispalense que, bajo el proyecto del denominado Padrón Real, procuró aglutinar la producción cartográfica en un solo lugar (Sánchez Martínez, 2016). Por esta razón los registros cartográficos realizados en el nuevo continente debían ser entregados 
sólo en tierras Ibéricas, al grado de conllevar radicales órdenes que implicaban atar pesas de plomo a los mapas en las travesías marítimas para ser lanzadas al fondo del océano en caso de que el buque cayera en manos enemigas. Por ello es posible que gran parte de la cartografía del nuevo mundo resida en el fondo del océano atlántico (Sánchez Cabra, 1998).

Pero si algo ha demostrado este aciago panorama es que los rudimentarios proyectos de nación latinoamericanos se encontraban más urgidos que nunca del florecimiento del viaje cartográfico en sus entrañas. El viaje, como metáfora de la formación del hombre y la sociedad moderna, se había consolidado como la mejor alternativa para la adquisición del conocimiento a lo largo del periodo de la colonia, situación que se incentivó, en una escala local, con el propósito de trazar la nación. Así, los mapas juegan un papel representativo crucial, en su dimensión simbólica, en el proceso de construcción del imaginario nacional. Un mapa, como imagen visual, puede valerse de su capacidad de reiteración para arraigarse en el imaginario de una sociedad. De tal manera que, mediante la reproducción secuencial de un mapa, los contornos y límites internacionales de un territorio forman una imagen fija en el imaginario colectivo, a tal punto que sus miembros puedan identificarse -incluso sólo- con el croquis de aquel territorio limitado que se ha denominado nación (Díaz et al., 2013). Esta función visual del mapa, pone el acento sobre aquello que podría denominarse una imagen geográfica. A este respecto "[l]a imagen geográfica suele poner en escena un esfuerzo, [...] por miniaturizar el mundo como una estrategia para asignarle un orden, entenderlo y en definitiva, situarnos en él." (Lois y Hollman, 2013, pág. 19) La imagen geográfica es pues el resultado de un vínculo indisociable que señala el clima de emergencia cartográfica-visual que circundaba los proyectos nacionales latinoamericanos.

El objetivo preliminar de las empresas cartográficas y etnográficas fue el establecimiento de lo que se comprende como cultura oficial, es decir, el reconocimiento institucional de las razas o fenotipos, tradiciones, religión, vestuarios, arquitectura, reliquias, etc., que se enarbolan como parte del propósito de la construcción del imaginario de nación. Este modelo es extensible a los casos colombiano y mexicano; dos naciones que han sostenido una relación de similitud desde la consolidación de su independencia, pues en

\footnotetext{
* Este aspecto en particular propiciado, por una parte por la intervención de los Estados Unidos en México (1846-1848), y por otra en la fragmentación del territorio Grancolombiano representado en la Nueva Granada, Venezuela y Ecuador (1830-1831), posteriormente agudizado con la pérdida definitiva de Panamá -tras otra intervención

Estadounidense en 1903-, es un fenómeno que pudo tener repercusiones negativas en el proceso de formación de identidad nacional, puesto que, como se ha mencionado anteriormente, la reiteración de un mapa, como límite de un croquis reconocible por su población, se consolida en el
}

principio son comparables en tanto han sufrido sucesivas mutilaciones del territorio*, ingentes guerras intestinas a lo largo del siglo XIX y una inestabilidad política y económica que aletargó los procesos de desarrollo económico y civil; todo ello sumado a las estrechas relaciones culturales y políticas que han hermanado a sus pueblos en un imaginario de nación bastante similar (Stafford, 2013). Es preciso aclarar que si bien las historias de México y Colombia pueden considerarse paralelas, México ha gozado de un mayor o más prematuro desarrollo económico, pues incursionó primero en los ámbitos del comercio exterior, debido en parte a la infraestructura portuaria y ferroviaria propia y de los Estados Unidos, pero también a que las características del territorio no representaron una prueba tan difícil de superar como en el caso de Colombia, cuya extensa región montañosa y condiciones climatológicas impidieron ver terminado el ferrocarril hasta inicios del siglo XX, mientras que México ya gozaba de dicho beneficio desde el periodo finisecular decimonónico (Stafford, 2013). Esta situación se verá reflejada en otros aspectos, como la carrera militar y la infraestructura comercial y educativa. Con todo, resulta curioso que los proyectos cartográficos neogranadinos, iniciados hacía finales de la década de 1840, aventajan por unos cuantos años el inicio del proyecto mexicano e incluso al estadounidense (Sánchez Cabra, 1998).

\section{Especulación político-geográfica en la Nueva Granada}

Agustín Codazzi, consolidado como la figura cartográfica más importante de la historia de Colombia, es la pieza clave para entender el proyecto cartográfico neogranadino. El ingeniero y militar italiano, llegó a la Nueva Granada, tras fungir como autor de un conglomerado de obras geográficas que determinarían los derroteros nacionales Venezolanos, a saber: el Mapa General de la República de Venezuela de 1839, el Atlas Físico y Político de la República de Venezuela de 1840 (Imagen 2), y el Resumen de la Geografía de Venezuela de 1841. (Barrios B., 2012) Una vez en la Nueva Granada -a donde llegó huyendo tras la derrota política del general José Antonio Páez, para quien trabajó en Venezuela-, el gobierno de Tomás Cipriano de Mosquera lo buscó para consolidar el proyecto de la Carta Geográfica de la Nueva

imaginario del ciudadano. ¿Cómo se consolida una imagen de nación si no se puede garantizar la defensa del territorio o, en definitiva, no se sabe cual territorio, y por cuanto tiempo, delimita la nación? La respuesta a este tipo de fenómenos puede encontrarse en los himnos, rituales cívicos como el juramento a la bandera- y gran parte de la literatura costumbrista, donde se exaltan los valores de la soberanía, la defensa del territorio y hasta se dibuja un enemigo común: Los Estados Unidos de Norte América. (Gutiérrez Viñuales, 2010, pp. 625 - 631) 
Granada, el cual terminaría convirtiéndose en la Comisión Corográfica de la Nueva Granada, empresa que tendría lugar entre 1850 y 1859 , y que respondió a la política de modernización económica que comenzó a gestarse en la primera administración del general Tomas Cipriano de Mosquera y que alcanzó su máxima expresión bajo el mandato de José Hilario López (Sánchez Cabra, 1998). Como mencionaba el secretario de relaciones Exteriores, Cerbeleón Pinzón, en el informe presentado al Congreso Constitucional de 1849, "[e]s incuestionable la urjente necesidad de que se levante la carta jeográfica de la República [sic]." (pág. 197)

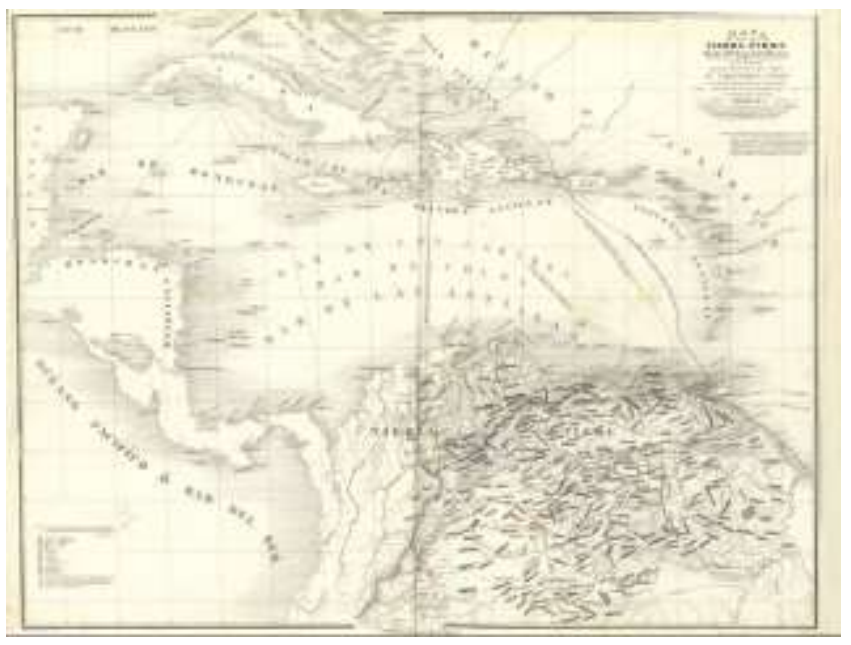

Imagen 1. Agustín Codazzi. Mapa de las Costas de Tierra-Firme desde el Orinoco hasta Yucatán. En Atlas Físico y Político de la República de Venezuela. 1841. Biblioteca Nacional de España.

Aunque para la nación era "incuestionablemente urgente" el levantamiento de una carta geográfica, situación que la ratifica como iniciativa gubernamental, ello no fue razón, ni para llevarla a feliz término -en el tiempo previsto-, ni para evitar que lamentablemente se viese truncada por un mandato sucesor ${ }^{*}$. Empero nada de esto resta importancia al proyecto cartográfico, pues como se verá, no sólo fue la necesidad el motor de su formación, sino también las loables intenciones de los hombres de luces que a bien tenía la tarea de llevar las riendas de la nación. Respecto al proceso de indagación sobre los orígenes de los proyectos cartográficos en la Nueva Granada, es primordial señalar que los fundamentos filosóficos sobre los cuales se forjaron, son fruto de la visión ilustrada de Francisco José de Caldas, quién vio en las disciplinas geográficas un insospechado valor ideológico, argumentando que el conocimiento físico del territorio nacional brindaría, en suma, una identidad, o por lo menos resultaría fundamental en la correcta formación de valores

\footnotetext{
* Los objetivos del gobierno conservador de José Hilario López, poco coincidían con las intenciones de política económica librecambista de los
}

culturales, políticos y económicos. Caldas difundió entre la distinguida sociedad santafereña, una idea capital para el desarrollo del país, la cual comprendía a la geografía como base fundamental de toda especulación política. En consecuencia, el primer paso a dar en busca de la prosperidad de la nación, radicaba en el levantamiento de una carta soberbia y digna de la Nueva Granada. En las propias palabras de Caldas,

[s]i se formase una expedición geográficaeconómica destinada á recorrer el Virreinato; [...] si todas las provincias contribuyesen con un fondo formado por los pudientes y principalmente por los propietarios; [...] no hay duda que dentro de pocos años tendríamos la gloria de poseer una obra maestra en la geografía y en la política, y de haber puesto los fundamentos de nuestra prosperidad. (1808, pág. 1175)

Puede decirse que las ideas de Caldas se convirtieron entonces en una suerte de programa nacional de desarrollo que resonaría a mitad de la centuria en la necesitada Nueva Granada. El orden de la nación, la división territorial, la estadística sobre los recursos naturales e industriales y el establecimiento y conocimiento de las vías de comunicación fueron los intereses y objetivos del proyecto nacional hacia mediados del siglo XIX, de modo que la carta geográfica de la República fue el medio para realizarlos.

Siendo una empresa de orden institucional, el gobierno del presidente José Hilario López, firmó un contrato con el general Agustín Codazzi en 1849, para el levantamiento de la Carta Geográfica de la Nueva Granada, aunque en realidad se le vinculó al proyecto bajo el nombre de ingeniero de caminos y no como ingeniero geólogo, debido a la falta de presupuesto y su condición de militar extranjero. En los artículos del contrato de Codazzi puede apreciarse la verdadera magnitud de la tarea encomendada. El primer artículo lo comprometía a formar una descripción completa de la Nueva Granada, y a levantar una carta general, un mapa corográfico de cada una de sus provincias, todo dentro del término de seis años contados desde el día $1^{\circ}$ de enero de 1850 . El segundo artículo estipulaba que todas las descripciones y mapas debían tener la extensión, claridad y exactitud necesarias para que el país pudiera ser estudiado y conocido en todas sus relaciones. El artículo tercero establecía una periodicidad anual para la entrega de informes y mapas con ciudades, villas, cantones, aldeas y cuantos detalles pudiese contener los planos de las provincias exploradas, según la escala que se ha señalado para formarlos y que por regla general consistía

liberales, razón por la cual la Comisión se vio posteriormente perjudicada por problemas financieros. 
en una pulgada para cada legua cuadrada. La cuarta parte del contrato evidenciaba una preocupación militar por parte del gobierno, estipulando que toda ventaja económica y militar que pueda brindar la zona debe estar registrada en los informes y mapas. El quinto artículo hablaba sobre las tareas encomendadas al término de las exploraciones, las cuales consistían primordialmente en presentar, siempre dentro del límite de seis años, la Carta General de la Nueva Granda y su respectiva descripción, las cuales debían guardar las mismas proporciones y calidad que la realizada por el general en Venezuela (Caro Molina, 1955).

Es claro, asumiendo lo expuesto hasta aquí, que la principal motivación para la formación de un proyecto cartográfico, radica en dos aspectos centrales: la necesidad geográfica, fincada en el impedimento de la defensa del territorio nacional, y el anhelo ilustrado del establecimiento de la cultura oficial del país. Sin embargo, sería completamente ingenuo quedarse con la mera reconstrucción ideológica del proyecto geográfico neogranadino. Si bien con ello se demostraron en cierta medida las intenciones de las imágenes y el contexto en el que se creó el proyecto, no puede ignorarse un componente esencial en plan de dimensiones y repercusiones nacionales. En este sentido, es notorio que la exploración del territorio se debió realizar también con el objetivo de atraer, tanto inversión, como extranjeros que supieran explotar la tierra, especialmente ingleses y estadounidenses.

En consecuencia, es posible afirmar que el programa cartográfico y etnográfico de la Nueva Granada "[...] fue concebido como una obra para promover la inmigración a través de la publicación de información sobre las ventajas del territorio neogranadino y las bondades de su población." (Villegas Vélez, 2014, pág. 318)

Visto así, las exploraciones territoriales procuraron construir un prisma, cuya óptica podría cambiar la visión de un desolador panorama de emergencia cartográfica y económica de una joven nación, por uno de atractivas oportunidades mercantiles para industriosos extranjeros. Dicha ostentación tendenciosa, repercutió directamente en la producción del imaginario nacional, pudiendo aducirse entonces que las imágenes producidas en aquel momento, fueron hechas con un objetivo persuasivo, más que ilustrativo o educativo. Finalmente, los trabajos y las cartas levantadas por Codazzi, sólo fueron publicadas hasta 1890 por Manuel María Paz y Felipe Pérez -pintor y dibujante, el primero, y escribano el segundo, durante la Comisión

\footnotetext{
* El título completo es: Atlas geográfico e histórico de la Republica de Colombia (Antigua Nueva Granada) : el cual comprende las repúblicas de Venezuela y Ecuador con arreglo a los trabajos geográficos del general de ingenieros Agustín Codazzi ejecutados en Venezuela y Nueva Granada.
}

Corográfica- bajo el nombre de Atlas geográfico e histórico de la República de Colombia* (Imagen 3)

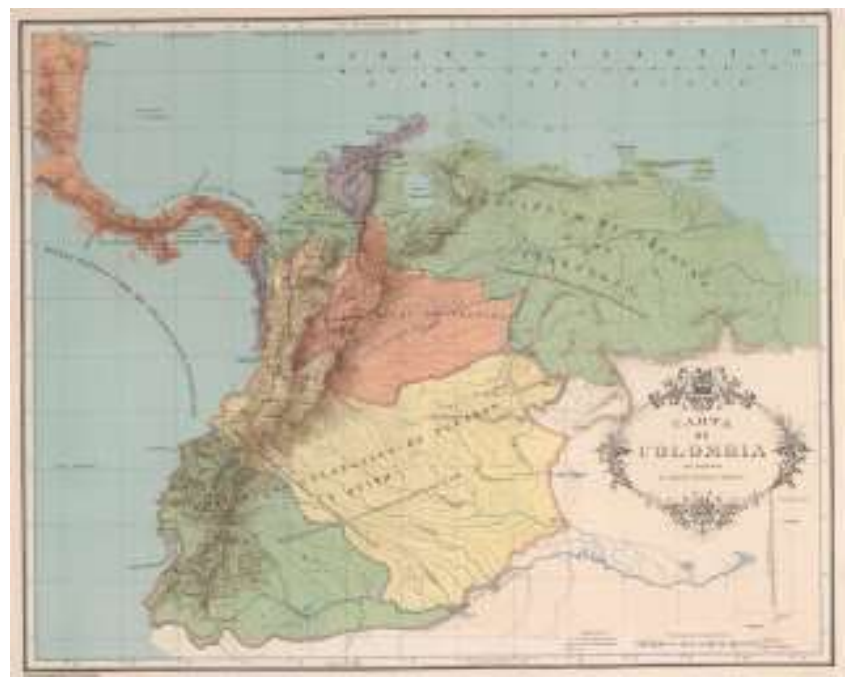

Imagen 3. Manuel María Paz. Carta de Colombia que representa las disposiciones Coloniales. Atlas geográfico e histórico de Colombia. Imprenta A. Lahure, 1889.

\section{Del vacío cartográfico al imaginario del régimen}

Puede encontrarse en el trabajo cartográfico de Antonio García Cubas, una síntesis ilustrativa del panorama cartográfico del México post-independista; una extensa obra fruto de una verdadera vocación de servir a su país y nacida, en parte, de la penosa situación que le tocó vivir durante la intervención estadounidense en territorio mexicano, y de los años de trabajo que realizó en la Dirección General de Colonización e Industria (1851), institución que después se convertiría en la Secretaría de Fomento en 1853. Fincado en las ideas independentistas, García Cubas ostentaba una educación científica adquirida en el Colegio Nacional de Minería, la cual combinaba con una inusitada pasión por las artes gráficas, trabajo que aprendió a realizar, en la técnica del grabado, bajo la tutela de Luis G. Campa, en la Academia de San Carlos; compartiendo espacio con algunos grandes artistas del siglo XIX mexicano como Eugenio Landesio y José María Velasco (Carrera, 2011). El trabajo cartográfico de García Cubas, inscrito en un lánguido panorama geográfico, puede definirse como una tarea que, "[...] más que crear un mapa preciso; quería nutrir la anémica geografía de la nación”. (Carrera, 2011, pág. 147) Bajo este principio presentó su primer trabajo cartográfico en 1857, cuando al servicio de la Sociedad Mexicana de Geografía y Estadística -SMGE-, presenta

Construida la parte cartográfica por Manuel M. Paz, Miembro de la Sociedad de Geografía de Paris. y redactado el texto explicativo por el doctor Felipe Pérez. Todo de orden del Gobierno Nacional de Colombia. 
la Carta general mayor escala. No obstante dicho mapa se integraría en un proyecto de mayor alcance que representaría el primer Atlas de México publicado en 1858: el Atlas geográfico, estadístico é histórico de la Republica Mexicana. Su trabajo continuaría con la publicación de Memoria para servir a la Carta General de la República Mexicana, en 1861; posteriormente con la Carta general de la República Mexicana de 1863 inspirada por la Commission scientifique du Mexique, que tuvo lugar durante el imperio de Maximiliano, bajo la premisa de que la ciencia cartográfica mexicana era deficiente-; seguida por Curso elemental de geografía universal dispuesto con arreglo á un Nuevo método que facilite su enseñanza en los establecimientos de instrucción de la República (sic), en 1869; para desembocar en la publicación de The Republic of Mexico in 1876. Esta obra tuvo gran peso ideológico y visual sobre la posterior producción cartográfica y litográfica del país. Si hasta antes de 1876 el trabajo de García Cubas había oscilado entre los proyectos de la SMGE -comprendidos como empresas nacionales- y trabajos de iniciativa particular, en este libro, el cartógrafo acentuó sus intereses personales al servicio de la patria, pues busca desestimar las perversas fabulaciones que extranjeros habían hecho de las razas, usos y costumbres mexicanos.

Así pues, la preocupación de García Cubas se centró en ofrecer una nueva y corregida forma de comprender la diversidad cultural de su país; objetivo que alcanza de manera más cabal en el Atlas pintoresco e histórico de los Estados Unidos Mexicanos, publicado por la casa Debray y Sucesores en 1885 (Imagen 4).

Sus ideas ilustradas, su pasión por el conocimiento científico, su amor por la patria -acentuado por las intervenciones americanas y francesas, y posteriormente enaltecida por el "triunfo de la República"-, el surgimiento de lo que se denominó la República Restaurada, y el proyecto de nación impulsado por el gobierno de Porfirio Díaz, son todos fenómenos sociales que repercutieron en él y en los intereses políticos, sociales y culturales, que imprimió en su extensa obra. Jesús Márquez (2012), resume gran parte de la efervescencia política e ideológica del siglo XIX, que bien podría comprenderse como la descripción exacta del momento histórico del cual es fruto el Atlas pintoresco de García Cubas.

Durante la primera mitad del siglo XIX se desarrolló en nuestro país una sensibilidad

\footnotetext{
* En The Republic of México in 1876, García Cubas escribe: "Este libro ha sido escrito con la visión de remover las impresiones equivocadas que pueden haber quedado en las mentes de lectores de aquellos trabajos cuyos intentos malvados, o su deseo de adquirir notoriedad como novelistas, se habían escrito y publicado sobre diferentes recuerdos foráneos de la nación Mexicana." (p.5 la traducción es propia) La molestia de García Cubas había sido propiciada, en particular, por The Human Race, una obra del científico francés Louis Figuier, cuya publicación se produjo en 1872,
}

romántica, preocupada por dar forma a un alma colectiva. Pero debido a los conflictos políticos, ello no desembocó en alguna suerte de cultura e identidad nacionales, [...]. Hasta antes de 1867, las artes, la historia y el periodismo se utilizaron para atacar o defender una u otra postura política. Fue precisamente al triunfo de la República cuando una generación de intelectuales y artistas se unió a la ideología y el proyecto político del grupo liberal y se propuso definir "lo mexicano". Para este grupo, una vez derrotados los conservadores en el campo de batalla, el arte debía estar comprometido con las causas del Estado; a través de la cultura se podría modelar una conciencia colectiva y establecer las bases políticas e ideológicas de la República. Por eso, desde la época restaurada (1867-1876) se generó un movimiento nacionalista que abarcó las letras, las manifestaciones plásticas, la música, la historia, la elaboración de libros escolares y sobre todo la fundación de instituciones culturales. (pág. 127)

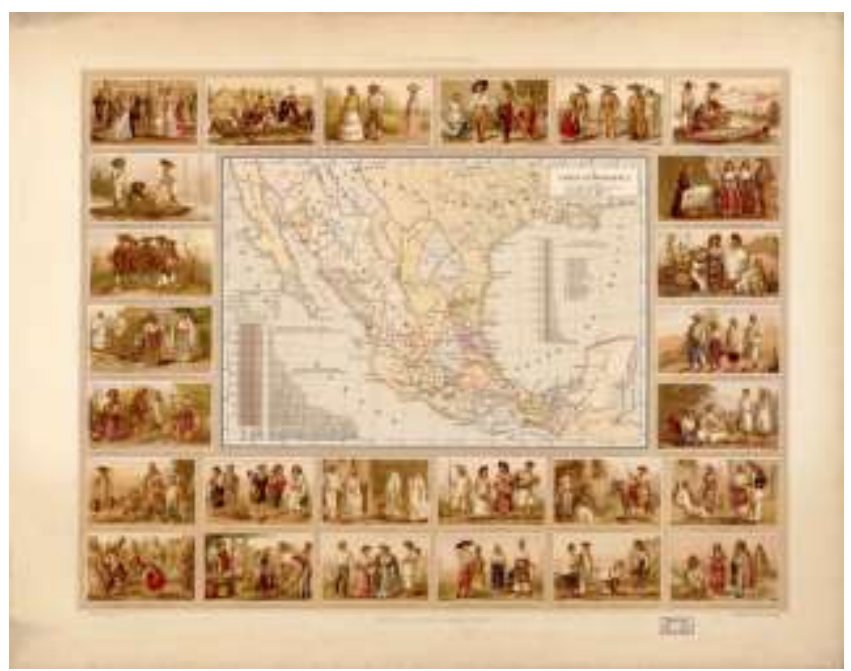

Figura 4. Antonio García Cubas. Il Carta etnográfica. Atlas pintoresco e histórico de los Estados Unidos Mexicanos. 1885.

De tal modo, otras publicaciones, con afanes similares a la de García Cubas, tuvieron lugar en el seno de la República Restaurada. Entre ellos, vale destacar México Pintoresco, Artístico y Monumentalt de Manuel Rivera

donde, bajo el mote general de "Red Race", se deforma sobre manera la imagen del indígena mexicano y otras razas del continente americano.

† El título completo de la obra es México pintoresco artístico y monumental: vistas, descripción, anécdotas y episodios de los lugares más notables de la Capital y de los Estados, aún de las poblaciones cortas, pero de importancia geográfica o histórica: las descripciones contienen 
Cambas, publicado en tres volúmenes, entre 1880 y 1883; y México A Través de los Siglos [...] de Vicente Riva Palacio, obra completada en 1889. El texto de Riva Palacio se convirtió en un referente obligado en el proceso de descripción de la nación, estableciendo además el guion historiográfico por excelencia para la República Mexicana, el cual es aún reconocible en los libros gratuitos de texto de la Secretaría de Educación Pública (SEP).

Otro aspecto fundamental del contexto de creación de las imágenes cartográficas mexicanas del siglo XIX, es el factor económico internacional. Los tópicos y clasificaciones de las la cartas abarcan minería, agricultura, orografía, hidrografía, entre otras; no resulta difícil imaginar entonces que el trabajo de García Cubas, y otros cartógrafos de la época, sirviese como un gran inventario de los recursos nacionales que, tanto a los terratenientes locales, como a los inversionistas extranjeros, pudiera servir de muestrario para atraer posibles inversiones. Esta observación se sustenta ipso facto al percatarse de que la gran mayoría de álbumes cartográficos y atlas, particularmente el Atlas pintoresco e histórico de 1885, fueron publicados en tres idiomas diferentes: español, inglés y francés. Paradójicamente, el afán académico de García Cubas, de hacer frente a las malintencionadas descripciones de viajeros foráneos, fue un instrumento al servicio de los mismos, quienes encontraron en su dispendiosa labor, una profusa carta de invitación. La sociedad del siglo XIX, en un curioso ejercicio de malinchismo decimonónico, entregaba gran importancia al papel de la inmigración europea en la construcción de la nación mexicana. "Se afirmaba que, una vez liberada la feraz América Septentrional del yugo de una España decadente, llegarían de Europa hombres laboriosos que transformarían los páramos en vergeles y la variopinta, atrasada y supersticiosa población mexicana en una nación próspera y moderna." (Pani, 2012, págs. 627-628) De tal modo, no es descabellado considerar que la cartografía mexicana, también pudiese obedecer a intenciones de tipo económico, más particularmente, que sirviera al propósito de atraer inversión extranjera al territorio mexicano.

Se puede asumir que las imágenes cartográficas del México decimonónico, también se produjeron bajo una amplia gama de necesidades, y que a la luz de los preceptos mercantiles de un contexto que favorecía el liberalismo económico, se encontró en ellas una alternativa brillante para combinar el afán reivindicatorio de su gente y contribuir al llamado de capital inversionista de cara al nuevo siglo.

\section{Conclusiones}

La somera reconstrucción del contexto sociopolítico y cultural del México decimonónico y el incipiente proyecto de la Nueva Granada, permiten plantear bases para comprender el surgimiento de los imaginarios nacionales latinoamericanos como respuesta a un conjunto de condiciones propicias, que van desde la necesidad hasta la oportunidad: la necesidad de encontrar una forma de representación de lo propio frente a las anquilosadas herencias coloniales que fueron desdeñadas desde la independencia, y una oportunidad de imaginar qué nación se deseaba construir. Sobre este punto, se ha aclarado cabalmente que imaginar y construir la nación son dos procesos diferentes que hacen parte de una misma causa. La construcción de la nación, es un camino accidentado que debe sobrepasar diferentes obstáculos como el desconocimiento del territorio, las arraigadas identidades locales separatistas $y$ las evidentes carencias económicas. Por su parte, la imaginación de la nación deriva de la posibilidad misma de edificar un proyecto bajo una narrativa histórica que exalte lo que se ha denominado como cultura oficial, y que aglutine la cultural y la definición de lo propio a través de la cual una nación se describe, para sí, y para las demás. De tal modo, la imagen cartográfica del siglo XIX fue producida con el objetivo de redescubrir su territorio, razas, costumbres y riquezas naturales, tanto para sus propios habitantes, como para los ojos de exterior. Es por ello que no resulta arriesgado afirmar que muchas de las incipientes naciones americanas, principalmente los Estados Unidos Mexicanos y la entonces Nueva Granada, encontraron en la cartografía la respuesta a sus jóvenes proyectos de imaginario nacional, o en suma, gracias a ella lograron, por fin, trazar la nación.

\section{Referencias}

[1] Anderson, B. (1993). Comunidades Imaginadas. Reflexiones sobre le origen y la difusión del nacionalismo. México, D. F., México: Fondo de Cultura Económica S.A. de C.V.

[2] Barrios B., J. V. (2012, Enero-Diciembre). La obra geográfica de Agustín Codazzi y el rompecabezas nacional (1830-1850). Anuario GRHIAL, 6, 43-64.

[3] Caldas, F. J. (1808). Estado de la geografía del Virreinato de Santafé de Bogotá. Bogotá.

[4] Caro Molina, F. (1955, Primer y segundo trimestre). CONTRATA. Adicional a la que se ha celebrado para el levantamiento de la Carta Geográfica de la República. Enero de 1850. Boletín de la Sociedad Geográfica de Colombia, XIII (45 y 46), 1-28. 
[5] Caro Molina, F. (1955, Primero y Segundo Trimestre). CONTRATA. Para el levantamiento de la Carta Geográfica de la Nueva Granada. Mayo de 1849. Boletín de la Sociedad Geográfica de Colombia, XIII (45 y 46), 1-28.

[6] Carrera, M. M. (2011). Traveling from New Spain to Mexico: Mapping Practices of Nineteenth-Century Mexico. Londres: Duke University Press.

[7] Centeno, M., \& Ferraro, A. (2013). State Building in Latin America and Spain Republics of the Posible. Ney York: Cambridge University Press.

[8] Codazzi, A. (1841). Atlas Físico y Político de la República de Venezuela. Paris: Thierry Freres.

[9] Codazzi, A. (1856). Informe sobre láminas de la Comisión Corográfica. El Porvenir.

[10] Díaz Ángel, S., Muñoz Arbeláez, S., \& Nieto Olarte, M. (2013). Desemsamblando la nación. El caso del Atlas geográfico e histórico de Colombia de 1889. En O. R. (ed.), Ensamblado en Colombia. Ensamblando Estados. (Vol. 1, pp. 143-178). Bogotá: Universidad Nacional de Colombia.

[11] Elliot, J. H. (2010). ¿Empezar de nuevo? El ocaso de los imperios español y británico en América. En G. Jiménez Condinach, Construyendo Patrias. Iberoamérica 1810-1824. Una reflexión (pp. 2764). México, D. F., México: Fomento Cultural Banamex, A. C.

[12] Figuier, L. (1872). The human race. New York: D. Appleton and Co., Broadway.

[13] García Cubas, A. (1858). Carta general de la República Mexicana. México: Imprenta de Lara.

[14] García Cubas, A. (1876). The Republic of Mexico in 1876. México: La enseñanza.

[15] García Cubas, A. (1885). Atlas pintoresco e historico de los Estados Unidos Mexicanos. México: Debrey Sucesores.

[16] García García, J. (1994, Julio - Septiempbre). Nación, identidad y paradoja: una perspectiva relacional para el estudio del nacionalismo. Reis: Revista Española de Investigaciones Sociológicas(67), 165-183.

[17] García, J. A. (2011). La formación de identidades y los imaginarios nacionales en Cuba a inicios del siglo XIX. Procesos. Revista ecuatoriana de historia., 37-66.

[18] Gutierrez Viñuales, R. (2003). El papel de las artes en la construcción de las identidades nacionales en Iberoamérica. Historia mexicana(53), 341-39.

[19] Gutiérrez Viñuales, R. (2010). Arte en la Sudamérica hispana en tiempos de la independencia (1809-1825). En G. Condinach, Construyendo patrias. Iberoamérica 1810-1824. Una reflexión. (Vol. II, pp. 599-653). Ciudad de México: Banamex.

[20] Hobsbawm, E. J. (1991). Naciones y nacionalismo desde 1870 Barcelona: Crítica.

[21] Lois, C., \& Hollman, V. (2013). Geografía y cultura visual. Los usos de las imágenes en las reflexiones sobre el espacio. Rosario, Argentina: Prohistoria Ediciones; UNR.

[22] López Alves, F. (2013). Visions of the National. Natural Endowments, Futures, and the Evils of Men. En M. Centeno, \& A. Ferraro, State and Nation Making in Latin America and Spain Republics of the Possible (pp. 282-306). New York: Cambridge University Press.
[23] Márquez Carrillo, J. (2012). Los arrestos de la patria. Política artes e identidad nacional en México 1867-1920. Puebla: Benemérita Universidad Autónoma de Puebla.

[24] Pani, E. (2012, Octubre-Diciembre). Ciudadanos Precarios.Naturalización y Extranjeria en el México Decimonónico. Historia Mexicana, 62(2), 627-674.

[25] Pérez Vejo, T. (2003, Octubre-Diciembre). La construcción de las naciones como problema historiográfico: el caso del mundo hispánico. Historia Mexicana, 53, 275-311.

[26] Pini, I. (1997). Aproximación a la idea de "lo propio" en el arte latinoamericano a fines del siglo XIX y comienzos del siglo XX. Historia Crítica, 5-15.

[27] Pinzón, C. (1994). Informe del Secretario de Relaciones Exteriores al Congreso Constitucional de 1849. En E. Sánchez, Gobierno y Geografía. Agustín Codazzi y la Comisión Corográfica de la Nueva Granada (p. 197). Bogotá: El Áncora Ediciones.

[28] Sánchez Cabra, E. (1998). Gobierno y geografía. Agustín Codazzi y la Comisión Corográfica de la Nueva Granada. Bogotá: El Áncora Ediciones.

[29] Sánchez Martínez, A. (2016). El imperio del mapa. El padrón real y la producción cartográfica de la casa de la contratación. En J. M. Moreno Martín, \& S. Raffaelli, Dueños del mar, señores del mundo. Historia de la cartografía naútica española (pp. 44-59). Madrid, España.

[30] Stafford, F. (2013). Construction of National States in Latin America, 1820-1890. En M. Centeno, \& A. Ferraro, State Building in Latin America and Spain. Republics of the Possible (pp. 25-55). New York: Cambridge University Press.

[31] Villegas Vélez, Á. A. (2014). Representación moderna, paisajes y poblaciones en las acuarelas de la Comisión Corográfica. En J. D. Cortés Guerrero, El bicentenario de la Independencia: legados y realizaciones a doscientos años (pp. 315-344). Bogotá, Colombia: Universidad Nacional de Colombia. 